[Special Issue on Research and Social Justice]

\title{
Qualitative Research as Social Justice Practice with Culturally Diverse Populations
}

Heather Z. Lyons and Denise H. Bike

Loyola University Maryland

Lizette Ojeda

Texas A\&M University

Adanna Johnson

Loyola University Maryland

Rocío Rosales

University of LaVerne

Lisa Y. Flores

University of Missouri, Columbia

\begin{abstract}
The qualitative research process can offer counselors and psychologists the opportunity to participate in social justice practice. Qualitative research contributes to social justice when researchers promote the following principles: equity, access, participation, and harmony for culturally diverse populations, those currently most at risk for acts of social injustice. In this manuscript we suggests ways in which qualitative approaches can provide a vehicle by which social justice can be enacted when researchers are conscious and deliberate about these intentions. To this end, we review and highlight best practices in socially just qualitative research processes across the following aspects of research: design, data collection, data analysis and interpretation, and application of findings.
\end{abstract}

Keywords: Qualitative research, social justice, counseling, research methodology 


\section{Introduction}

Reflecting the similarly situated impact of each, both qualitative research (Ponterotto, 2002) and social justice practice (Ratts, D'Andrea, \& Arredondo, 2004) have been deemed the "fifth force" in psychology and counseling. Indeed, qualitative research and social justice share a number of common elements. However, it is also possible to imagine instances of qualitative research that are not socially just and, naturally, of social justice research that is quantitative (Cokley \& Awad, 2013) or mixed methods (Ponterotto, Mathew, \& Raughley, 2013).

Historically, members of underrepresented groups have been excluded from psychological research (e.g., Arnett, 2008; McGuire \& Miranda, 2008), stereotyped (e.g., Alvidrez, Snowden, \& Kaiser, 2008; Herek, Kimmel, Amaro, \& Melton, 1991) and in some instances abused (Malone, Yerger, McGruder, \& Froelicher, 2006; Washington, 2006). Scholars have called for a repair of this history and an answer to the ethical imperative for socially just qualitative research (e.g., Denzin \& Lincoln, 2005; Malone et al., 2006). Assumptions that qualitative research is inherently socially just or better suited to the study of culturally diverse populations than other methodological approaches are injudicious. Therefore, careful deliberation on the ways that researchers may conduct qualitative research in a socially just manner, especially with culturally diverse populations, is needed and is the purpose of the present manuscript.

In this paper, we explore the ways in which qualitative approaches can provide a vehicle by which social justice practice can be enacted when researchers are conscious and deliberate about these intentions and provide examples of how social justice may be incorporated into each aspect of the qualitative research process. We provide practical examples from the extant literature intended to demonstrate the socially just practice of qualitative research with the understanding that the suggested practices may not be exclusively relevant to qualitative methodologies. Although pragmatic, and based upon previously conducted research, these suggestions are offered as aspirational, with the understanding that the level of interest each researcher's population has in engaging in the process as well as his or her motives for conducting research may influence the extent to which the various recommendations appear feasible. Further, in recognition that conducting research in a socially just manner is not an easy task accomplished by reading a single article, the present article serves merely to raise awareness and suggest skills that one might use.

First, an overview of the definition of qualitative research by which we are operating is warranted. Because of the diversity in the field of qualitative research in terms of paradigms and methods, pinning down a definition is difficult. For the purposes of this article, qualitative research is broadly thought of as the contextualized study of individuals, communities, systems, and concepts through interviews, observation, and artifacts (e.g., newspaper clippings, photographs, Internet sources). The resulting data are then interpreted with an attempt to explore new topics or populations, portray meaning, develop theory, and inspire action (Denzin \& Lincoln, 2005). Definitions of other terms relevant to this manuscript, including social justice and multicultural competence, are included in the introductory manuscript.

\section{Qualitative Research and Social Justice: Points of Confluence}


Numerous points of confluence between the elements of social justice practice and qualitative research exist, despite the diversity of qualitative methods and paradigms. Naturally, identification of these points of confluence does not rule out the possibility that other types of research would also intersect with social justice practice along the same or other points; however, qualitative research is the focus of this work. Areas of convergence include: (a) recognition that those practicing social justice and qualitative research place a premium on context and environment (Fouad, Gerstein, \& Toporek, 2006; Lewis, Ratts, Paladino, \& Toporek, 2011; Merchant \& Dupuy, 1996), (b) encouragement of intimate contact and ideally a healthy and reciprocal relationship between researcher and relevant constituencies (e.g., research participants, community members), (c) reflection on or management of the influence of this contact (Bell \& Goodman, 2006; Morrow, 2005), and (d) emphasis on an emic and inductive understanding of experiences, concepts and samples/communities (Bell \& Goodman, 2006; Denzin \& Lincoln, 2005). When conducting research with individuals from culturally diverse groups, these points of confluence become particularly salient (e.g., cultural environment may be particularly important to these populations). Furthermore, social justice oriented research may result in an increased level of responsibility to communities potentially vulnerable in research encounters (Washington, 2006).

\section{Four Aspirations of Socially Just Qualitative Research}

Here, and in the other papers that comprise this special issue, we borrow from Crethar, Rivera, and Nash's (2008) delineation of the common principles that underlie feminist, multicultural, and social justice counseling to broaden the view of socially just qualitative research. Specifically, Crether et al. (2008) identify four principles, conceptualized here as aspirations: equity, access, participation and harmony. Ideally, these aspirations are called upon to serve the individuals, communities, and concepts under investigation in socially just qualitative research.

Equity may broadly be described as a subjective sense of fairness. Researchers that aspire to be equitable might reflect on the research process (e.g., Are certain research tasks valued above others? If utilizing a research team, can team members take on tasks that capitalize on their strengths?), the content and focus of the research (e.g., choosing to study traditional healing practices for people of the African diaspora, gender inequalities in executive pay), or on research outcomes (e.g., Do the findings accurately represent the experiences of the community members? How can the findings be disseminated to the necessary stakeholders?). Access refers to one's right to power, information, and opportunity. In many ways, socially just qualitative research can help diminish barriers to these resources by asking relevant questions and distributing results in ways that are inviting to relevant communities and in a voice that is recognizable (Choudhuri, 2005; Morrow, Rakhsha, \& Castañeda, 2001). When qualitative researchers consider input from all of the relevant players and give community members the right to participate in decisions that affect their lives, then Crethar et al.'s third aspiration is attained. Qualitative research that is harmonious puts community and societal needs above that of the individual, including researchers' needs. Therefore, harmony would result in research that benefits the community as a whole, rather than resulting in outputs or processes of sole benefit to researchers (e.g., publications devoid of practical utility). 
These four aspirations can be used to guide decisions throughout the research process to maintain alignment with an objective of social justice. In the section that follows, we explore some ways in which these aspirations may become evident in the following aspects of the qualitative research process: development and preparation, data collection, data analysis and interpretation, and application (See Table 1 below for a summary of suggestions). As the qualitative research process is often iterative in nature, we use the term "aspects" rather than stages.

Table 1. Notable Features of Socially Just Qualitative Research

\begin{tabular}{|c|c|}
\hline $\begin{array}{l}\text { Aspects of Qualitative } \\
\text { Research }\end{array}$ & Notable Features (Social Justice Principle) \\
\hline Development and Preparation & $\begin{array}{l}\text { - Building relationships in the community of interest prior to } \\
\text { data collection (access) } \\
\text { - Involving community members and key stakeholders in } \\
\text { design (participation) } \\
\text { - Considering potential benefits and negative consequences } \\
\text { of research (harmony) } \\
\text { - If utilizing a research team, selecting culturally competent, } \\
\text { creative, and diplomatic members with strong critical } \\
\text { thinking skills (equity) }\end{array}$ \\
\hline Data Collection & 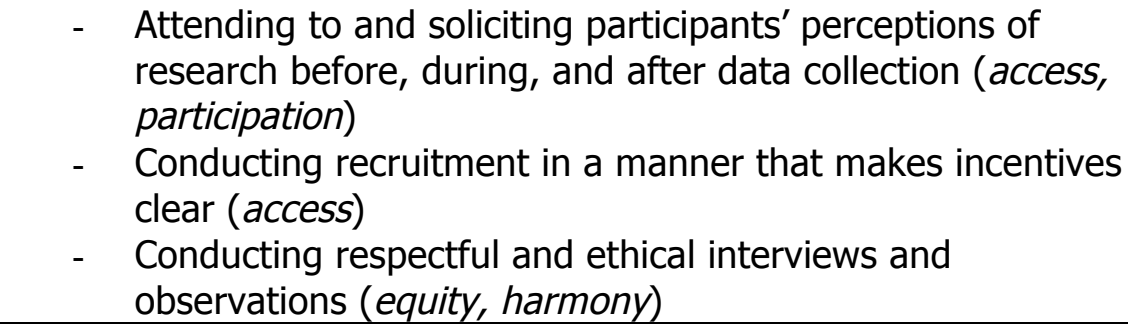 \\
\hline $\begin{array}{l}\text { Data Analysis and } \\
\text { Interpretation }\end{array}$ & $\begin{array}{l}\text { - Including a variety of data coders in terms of community } \\
\text { membership, access to power, and cultural background } \\
\text { (access, participation) } \\
\text { - } \\
\text { Recognizing the ways that researcher inputs may influence } \\
\text { data analysis and interpretation (equity, harmony) } \\
\text { - Improving the trustworthiness of the analysis and } \\
\text { interpretation through the use of participant quotes and } \\
\text { member checks (access, participation) }\end{array}$ \\
\hline Application & $\begin{array}{l}\text { - } \quad \text { Considering the practical utility of the project (harmony) } \\
\text { - } \quad \text { Involving community members in decisions about } \\
\text { applications of the results (access, participation) }\end{array}$ \\
\hline
\end{tabular}


Socially just qualitative researchers attend to the preparatory phases of research in an attempt to produce research that emphasizes equity, access, participation and harmony (Crethar et al. 2008). Development and preparation considerations may include topic selection, design, ethics, initial trustworthiness decision, and selection of research team members. In this section, design (e.g., working with communities to determine relevant research questions) and, when applicable, the selection of research team members are discussed from a social justice perspective.

\section{Design}

During every aspect of research, including design, researcher and participant identities are performed and interact (Morrow, 2005). Naturally then, cultural identities and backgrounds, including access to resources, may influence the content and process of the design of the study (Fouad \& Arredondo, 2007). Because the dominant racial and socio-economic cultures of the United States, commonly mirrored in academia, are interpreted as individualistic, task-oriented, and direct (Eide \& Allen, 2005), researchers may have been trained from a traditional, monocultural orientation where research questions are developed in isolation and then presented to participants during data collection. However, this method may be unfamiliar, uncomfortable, or even offensive to participants from many culturally diverse populations, particularly participants who commonly conceptualize their experiences through a collectivistic, indirect, relationship oriented cultural lens (Eide \& Allen, 2005).

Socially just researchers, therefore, would approach the conceptualization of the project, including research question development and other design activities, as an opportunity to begin building a collaborative relationship with the community being investigated. This can be done by involving community leaders or other key stakeholders within the community (Eide \& Allen, 2005; Lyons \& Bike, 2010). Although qualitative research that is informed by the criticalideological paradigm (e.g., Participatory Action Research) commonly includes community leaders as co-researchers by design, socially just qualitative researchers using approaches informed by other paradigms would not be prohibited from collaboratively working within the community being studied beginning in the early stages of a project.

However, Bell and Goodman (2006) caution social justice researchers about the potential tradeoffs of social justice research that is harmonious. Specifically, when asking questions that are of importance to marginalized or at-risk communities, researchers may need to understand that some criteria valued by academia (e.g., the use of strict inclusion or exclusion criteria) may not provide the answers sought by the community. Similarly, although filling a gap in the extant literature or completing one's dissertation in a timely manner may fit the goals of the traditional research academic, such an aspiration may be meaningless to the communities sought for participation. Bell and Goodman also encouraged researchers and communities to consider the consequences of their research findings to communities when designing studies. For example, researchers might reflect on the following questions: "Can the results suggest interventions that are too costly for communities to burden?" and "Is it possible that those interventions in which communities have invested are ineffective?" 


\section{Selecting Research Team Members}

Certainly not all qualitative methods necessitate the use of a research team (e.g., autoethnography). However, when research teams are utilized, team member selection must be intentional because of the need to implement culturally competent research practices throughout the process. Critical qualities of potential team members include multicultural competence, previous work with a similar population, and counseling skills (Lyons \& Bike, 2010). Members must be sophisticated in their cultural identity statuses, be in possession of strong abstract thinking skills, be creative, and have the ability to self-reflect. According to Smith (2012), this introspection may also include an examination of why the researcher desires to advocate for a population through social justice-oriented research. For example, if one is not a member of the population, thoroughly examining one's education about and experiences with the population along with a willingness to explore the potential biases can provide insight that may not only facilitate the research process, but aid in one's overall multicultural competence as a researcher. This requires a willingness to be vulnerable with other team members at the onset of the research project. Furthermore, as suggested in the literature (e.g., Hill, Thompson, \& Williams, 1997; Hill et al., 2005), successful team members possess skills, such as diplomacy, that facilitate equitable expression and contribution. Members in possession of these experiences and characteristics create a team more capable of non-defensively and productively interacting with each other and with members of the community being researched.

\section{Data Collection}

In qualitative inquiry, the process of data collection provides researchers with a unique opportunity to engage with communities in very intimate ways. Even ethical researchers who otherwise consider themselves multiculturally competent can fall prey to unintentional injustice (Denzin \& Lincoln, 2005; Morrow, 2005). Unintentional injustices are often subtle and prevent the data collection process from being one that truly honors the communities and individuals who participate in research. Therefore, social justice practice is arguably an integral part of respecting communities and ensuring that research is conducted only when necessary and is done with a focus on the best interest of the community. Here we will address the ways in which qualitative researchers can demonstrate respect to communities through thoughtful data collection.

\section{Participant Recruitment}

The opportunity to be an included population in research has been examined previously in the multicultural (Arredondo \& Perez, 2003) and social justice (Bell \& Goodman, 2006; Grayshield \& Mihecoby, 2010; Vera \& Speight, 2003) literatures. Recruitment provides the opportunity for meaningful participation because "when individuals are not permitted to participate in processes that influence their lives, they often lose a sense of control" (Crethar et al., 2008, p. 271). Involving participants requires attention to the sociocultural climate that impacts perceptions about research. Furthermore, researchers may come from academic communities that participants might perceive as removed and out of touch with their own lived experiences (Grayshield \& Mihecoby, 2010). These perceptions may arise from a lack of familiarity with research, prior experiences of exploitation or deception (Washington, 2006), or concerns about 
language fluency, which collectively can discourage participation from members from culturally diverse groups (Bowman, 1991; Washington, 2006). The following solutions are proposed.

Qualitative researchers can consider innovative recruitment strategies. Recruitment and incentives geared toward underserved populations must clearly explain the purposes of the research, and also take steps to communicate respect for participants. To this end, effective recruitment often involves building relationships with key community leaders, known as gatekeepers or stakeholders (Sixsmith, Boneham, \& Goldring, 2003). Relationship building with gatekeepers will require some level of community engagement from researchers (e.g., volunteering in or joining community agencies, connecting with stakeholders in the researchers' neighborhood of residence, religious service attendance). These leaders can connect researchers to potential participants, and as mentioned earlier, can collaborate with researchers to ultimately form a study that serves the community and yields results reflective of the community's members (Lyons \& Bike, 2010; Sixsmith et al., 2003). However, researchers should consider the factors that led to choosing which community stakeholders represent the population. On a related note, researchers should attend to gatekeepers' decisions about inclusion and exclusion, as well as the consequences of these decisions. At times, Western research values may conflict with what is valued in diverse cultural communities when researchers place importance on factors that are not inherently significant for the population (Smith, 2012).

Without gatekeeper support, especially for researchers who lack cultural (e.g., racial, economic, or geographical) commonality with the community of investigation, obtaining access to and cooperation from community members can be time consuming and difficult, if not fully prohibitive. In preparing for a study of Mexican immigrants' career development, one researcher (Shinnar, 2007) received a list of names of documented immigrant workers from a leader in a local church, which provided functional but not relational access to participants. On the other hand, in a study of gay parents, researchers (Lassiter, Dew, Newton, Hays, \& Yarbrough, 2006) immersed themselves in the participants' community through "an organization that provides social and recreational opportunities for gay and lesbian families" (Lassiter et al., p. 246) for one year prior to recruitment. Verbal invitations as well as paper and electronic solicitations were used to recruit participants and the researchers selected participants who self-identified as gay or lesbian parents-empowering participants to self-select and self-label, rather than imposing group membership on participants.

\section{Meaningful Participation}

More recently, issues of inclusion have garnered more attention in psychological research (e.g., Arredondo \& Perez, 2003; Bell \& Goodman, 2006; Vera \& Speight, 2003) with suggestions that research participation be extended to under-researched groups. Qualitative researchers need to make efforts to include culturally diverse populations in research, and individuals within these communities should be consulted about their needs during development and preparation and be given an opportunity to voice what they believe would be meaningful inquiry. Needs assessment allows for focused attention on that which disaffects particular communities (Lockyer, 1998; Reviere, 1996; Stufflebeam, McCormick, Brinkerhoff, \& Nelson, 1985). 
Another consideration related to meaningful participation is consent. Smythe and Murray (2000) discuss process consent in a manner that aligns with the principles of access and equity. Traditional consent takes place one time, at the outset of the project, and is conceived of in its entirety by the researcher. Process consent, by comparison, is an ongoing process and mutually developed by the researchers and participants. Participants engaged in process consent can remove their participation as well as their data at any point of the project (Smythe \& Murray), which can be particularly empowering for participants who are traditionally powerless over the results and final outcome of their data once they have consented for researchers to obtain it. Additionally, when participation is meaningful, members of the community must also be aware of and express their reactions to the data collection process conducted in their context. This perspective of empowerment involves researchers' understanding of community values, strengths, and needs (Crethar et al., 2008) in a way that attempts to redistribute power and promote greater access to resources and services (Sanders, 2000). Montero (2009) suggested that there should be a transformation of the role of researchers from "experts to dialoging participants" (p. 151), allowing researchers to remain vigilant to the needs of the community during the academic processes including providing the opportunity to dialogue and express concerns. When this is done, participants may experience the benefits of research participation to the extent that they choose.

\section{Data Analysis and Interpretation}

Opportunities exist for qualitative researchers to integrate social justice practice in the analysis and interpretation of their data. Analysis and interpretation of qualitative data involving multicultural populations provides an opportunity to represent the voices of understudied participants in a manner that is meaningful and faithful. Analysis involves the process of organizing and classifying data, which leads to pattern and relationship recognition in preparation for the interpretation or meaning making of data (Lyons \& Bike, 2010; Wolcott, 1994). We will focus on the ways that attending to researcher input and depiction of participant voice may promote social justice.

\section{Researcher Input}

Although paradigms vary in how researcher input is conceptualized (e.g. encouraging researcher objectivity, managing researcher bias, acknowledging researcher expectations), it is widely recognized that researchers are tools that may influence how qualitative data are analyzed and interpreted (Morrow et al., 2001). Historically, psychological research has been conducted and presented in a manner that minimizes acknowledgment of input in the process, methods, and conclusions made about the data. This has been touted as a more objective manner of evaluation. However, Smith (2012) argued that objectivity is not measurable, but distance (i.e., how close one is to belonging to a population or community) is. Although some distance may assist with one's ability to observe, it may be helpful to researchers to reflect on this distance and their own experiences. Specific to the present discussion is the role of cultural inputs. As cultural beings, researchers' identities (such as race, ethnicity, gender, social class, ability, nationality, and sexual orientation) and the researchers' demographic and cultural participation in or distance from participants' identities may influence which data are determined to be meaningful enough to be presented and what meanings are attached to these 
data (Morrow et al., 2001). Although diverse cultural experiences and distance may provide a unique lens through which to interpret data that can foster cultural sensitivity, researchers should be aware of how their cultural backgrounds may be a part of data analysis and interpretation. This attention to researcher input has the potential to create qualitative research that promotes the social justice aspirations for participation (e.g., allowing a trustworthy representation of participants' voices) and harmony (e.g., allowing community voices to overpower researchers').

Recognizing researchers' cultural inputs may be facilitated by the acquisition of multicultural awareness, knowledge, and skills (Sue, Arredondo, \& McDavis, 1992). Multicultural competence in the form of awareness may help qualitative researchers better recognize their own cultural perspective so that analysis and interpretation of the data remain close to participants' experiences and words. Multicultural knowledge can help researchers by equipping them with an understanding of a particular community's worldview and within-group differences. Finally, researchers competent in multicultural skills may have a greater appreciation for the diversity of ways that relevant data are communicated through interviews and observations (e.g., nonverbal gestures; Lyons \& Bike, 2010).

In addition to the importance of researcher multicultural competence in data analysis and interpretation, inclusion of either an auditor or multiple data coders who are diverse in terms of community membership, position and access to power, and cultural backgrounds may encourage researchers to acknowledge blind-spots, think creatively and flexibly, eschew groupthink and more thoroughly discuss data. For example, in a study of the resettlement experiences of people with mobility disabilities in post-conflict Sierra Leone, one of the researchers (who had lived and worked within the population) spoke both Krio and English, which helped while translating and conducting the interviews as well as coding and interpreting the data (dos Santos-Zingale \& McColl, 2006). During the latter phases, the researchers' different cultural experiences helped them recognize that the Western value of independence can raise problems when people with disabilities in that culture need additional support. However, in their community-oriented sample, interdependence was the norm. Expanding their view in this manner, it became clear to the researchers that in their sample the need for assistance was not perceived as distressing in and of itself; the lack of available assistance was. Involving multiple worldviews as well as attending to social justice aspirations in the process of research is important to represent the diverse experiences of participants.

\section{Trustworthy Representations of Participant Voice}

Socially just analysis and interpretation include faithfully representing the perspectives of study participants thereby promoting the quality of qualitative research. This quality indicator, specifically referred to as data trustworthiness (Morrow, 2005), may be facilitated in many ways including: the generous use of participant quotes, member checks, and involving participants and community members in analysis and interpretation. Beginning with the use of direct quotes, qualitative researchers are encouraged to include participants' quotes in research reports in addition to providing researchers' interpretation to provide readers with a better understanding of the given phenomenon from a participant's perspective (Corden \& Sainsbury, 2006; Fassinger, 2005). Including direct quotes also provides an opportunity to increase 
participant visibility and promote social justice by empowering a socially oppressed group to participate in the research process (Corden \& Sainsbury, 2006).

Member checks (Hill et al., 1997) or focus groups (Hill et al., 2005) can involve comparing the interpretation of researchers and that of participants or of representative members of the population being explored. This process can help confirm or disconfirm consistency and trustworthiness of data interpretation. A study of low-income African American grandmothers established trustworthiness of their interpretations by conducting member checks in which participants reviewed their transcripts for accuracy in capturing their voices (Simpson \& Lawrence-Webb, 2009). Another study on cross-racial therapy used member-checking procedures by inviting participants to a presentation and discussion of the findings to provide feedback on the interpretations made by the researchers (Chang \& Berk, 2009).

Although the examples provided above may be utilized in research informed by a variety of paradigms (e.g., post-positivistic, constructivist), the inclusion of participants or community members as researchers is typically associated with the critical-ideological paradigm. However, this practice is also consistent with the aims of other paradigms (Lyons \& Bike, 2010). Furthermore, this practice may facilitate research from paradigms that value promotion of researcher objectivity (e.g., Post-Positivism) or the management of researcher bias (e.g., Constructivism). Hearing from these constituencies may ensure that researchers' perspectives do not consume those of the participants under investigation.

\section{Application}

Research is an instrument and, as with any instrument, its benefits or its dangers rest upon its usage. There is neither implicit benefit nor danger in the instrument of research, but the research must be guided by a set of principles, which ensure the ultimate utility of that research. (Akbar, 2004, p. 685)

Identification of the applicability of a project to real world problems or circumstances (Glaser \& Strauss, 1967) has been described as a means of attesting to the quality and trustworthiness of qualitative research (Cutcliffe \& Harder, 2009; Marshall \& Rossman, 2006). Therefore, application of the research is a customary component of qualitative research, particularly socially just qualitative research. However, the ways that authors suggest or engage in application of their research varies largely based on the paradigm informing the qualitative method. For instance, post-positivist research places value on objectivity (Ponterotto, 2005), which tends to keep researcher and actor (e.g., practitioner) distinct. Therefore, the application of research is usually an enterprise that is separate from the research itself. That being said, the socially-just, post-positivist researcher may still assume the responsibility to disseminate research results in a format conducive to application (e.g., at community health fairs, a researcher sponsored breakfast) or to facilitate culturally-appropriate community responses. For example, following the conclusion of data collection, researchers conducting a qualitative study of the work experiences of unemployed African American women (Lyons, Evans, White, Nichols, \& Leckey, in preparation) utilized the results to intervene. Given that a number of participants spoke about their desire to become entrepreneurs, a non-profit agency designed to help lowincome women become small-business owners was invited to the data collection site to help 
participants, and others at the data collection site, meet this specific vocational goal. Participation in this outreach effort was voluntary.

Conversely, in qualitative research informed by a constructivist-interpretivist paradigm, researchers readily recognize their own subjective influence on the research process and also value the practical utility of theories and conclusions drawn (see Glaser \& Strauss, 1967). Yet, these researchers tend to compartmentalize research from the application of research. Despite these differences between post-positivist and constructivist-interpretivist researchers, the application of research is similar. That is, both researchers tend to make suggestions for research to be carried out by advocates or practitioners, individuals separate from those partaking in the research endeavor. For example, in a Grounded Theory study of highachieving women with disabilities, Noonan et al. (2004) proposed intervention strategies based on a model of disability identity that the authors constructed from the data. Similarly, in another Grounded Theory study, Simpson and Lawrence-Webb, (2009) utilized their research on African American grandmothers to identify areas of knowledge deficits for practitioners, particularly related to legal advocacy. Lassiter et al. (2006) explored the meaning of social justice terminology (e.g., empowerment) for gay and lesbian parents and then used their findings to guide practitioners. Finally, in attempting to understand the career development of Mexican immigrants, Shinnar (2007) included an assessment of needs, which shed light on the limitations of advocacy efforts when those efforts might cause disclosure of immigration status. By arming practitioners with empirically-based recommendations, practitioners are better equipped to successfully advocate for various populations.

Critical-ideological researchers tend to place a value on an undifferentiated relationship between research and application, often actively engaging in research-informed advocacy efforts (and advocacy-informed research efforts) over the course of the research cycle. For example, when Guishard et al. (2005) set out to engage in participatory action research exploring the origins and productivity of a grassroots parents organization centered on educational justice, they stated as their first research goal, the desire to "establish a community of youth researchers to study how adolescents, their mothers, and community members perceive the 'achievement gap' in terms of social class, race or ethnicity and opportunity inequities" (p. 40). Indeed, the researchers' roles were multi-faceted as they became co-researchers, mentors, and members of an organization attempting to provide a service to and empower a community. Furthermore, these researchers attempted to integrate Crethar et al.'s (2008) principles of participation and equity in that community members' had a say in how research was applied. The members of this research team, including community members, constructed a website to help disseminate research results.

Despite the diversity of ways that research can lead to socially just applications, each paradigm can aspire to provide community members, counselors and psychologists with access to resources that were not previously accessible. Although critical-ideological researchers may offer what appears to be the most obvious execution of research that is socially just, it is important to note that this research is labor intensive. Not all researchers and practitioners have the skill set, time or desire to engage in this type of research. Furthermore, a sole focus on critical-ideological paradigm may obscure the ways that other types of qualitative research may be socially just. Therefore, it will be useful for researchers to consider the ways that many qualitative research methods informed by a variety of paradigms may be used to foster social justice practice. 


\section{Conclusion}

As Crethar et al. (2008) noted about the practice of counseling, the present authors acknowledge that qualitative research does not inherently lead to social justice outcomes. Further, it is acknowledged that the ability to and interest in engaging in socially just qualitative research practices will vary with researchers' and participants' context and experience. Because counselors and psychologists are situated within privileged opportunity structures (Diemer, 2007), qualitative researchers-like counselors and psychologists-who are motivated by social justice may find that they must infuse social justice into their actions with intention, especially when interacting with communities not situated within the same opportunity structures. The present article was intended to provide some examples for how this can be accomplished. Each aspect of the qualitative research process offers researchers the opportunity to contribute towards social justice practice. Specifically, weaving social justice into the qualitative research process can happen successfully when researchers reflect on and integrate the social justice principles outlined in this article: equity, access, participation, and harmony (Crethar et al., 2008).

\section{Contact information}

Heather Z. Lyons, Ph.D., Associate Professor \& Director of Clinical Training, Department of Psychology, Loyola University Maryland Email: HZLyons@loyola.edu

Denise H. Bike, Ph.D., Visiting Affiliate Assistant Professor, Department of Psychology, Loyola University Maryland

Adanna J. Johnson, Ph. D., Assistant Professor of Psychology, Loyola University Maryland

Lizette Ojeda, Ph.D., Assistant Professor, Counseling Psychology Program, Department of Educational Psychology, Texas A\&M University

Rocio Rosales Meza, Ph.D., Assistant Professor, Psychology Department, University of La Verne

Lisa Y. Flores, Ph.D., Associate Professor, Counseling Psychology Program, Department of Educational, School, \& Counseling Psychology, University of Missouri 


\section{References}

Akbar, N. (2004). Paradigms of African American research. In R. L. Jones (Ed.), Black psychology ( $4^{\text {th }}$ ed., pp. 685-700). Hampton, VA: Cobb \& Henry.

Alvidrez, J., Snowden, L. R, \& Kaiser, D. M. (2008). The experience of stigma among Black mental health consumers. Journal of Health Care for the Poor and Underserved, 19, 874-893.

Arnett, J. J. (2008). The neglected 95\%: Why American psychology needs to become less American. American Psychologist, 63, 602-14.

Arredondo, P., \& Perez, P. (2003). Counseling paradigms and Latina/o Americans. In F. Harper \& J. McFadden (Eds.), Culture and counseling: New approaches (pp. 115-132). Boston, MA: Allyn \& Bacon.

Bell, M. E., \& Goodman, L. A. (2006). Seeking social justice for victims of intimate partner violence: Real world struggles in pursuit of systemic change. In R.L. Toporek, L. H. Gerstein, N. A. Fouad, G. Roysircar, \& T. Israel (Eds), Handbook for social justice in counseling psychology: Leadership, vision, and action (pp. 155-169). Thousand Oaks, CA: Sage Publications.

Bowman, P. J. (1991). Race, class and ethics in research: Belmont principles to functional relevance. In R. L. Jones (Ed.). Black psychology (3rd ed., pp. 747-766). Berkeley, CA: Cobb \& Henry.

Chang, D. F., \& Berk, A. (2009). Making cross-racial therapy work: A phenomenological study of clients' experiences of cross-racial therapy. Journal of Counseling Psychology, 56, 521536.

Choudhuri, D. D. (2005). Conducting culturally sensitive qualitative research. In M. Constantine \& D. W. Sue (Eds.), Strategies for building multicultural competence in mental health and educational settings (pp. 269-282). Hoboken, NJ: John Wiley \& Sons, Inc.

Corden, A., \& Sainsbury, R. (2006). Exploring "quality": Research participants' perspectives on verbatim quotations. International Journal of Social Research Methodology: Theory \& Practice, 9, 97-110.

Crethar, H. C., Rivera, E. T., \& Nash, S. (2008). In search of common threads: Linking multicultural, feminist, and social justice counseling paradigms. Journal of Counseling and Development, 86, 269-278.

Cutcliffe, J. R., \& Harder, H. G. (2009). The perpetual search for parsimony: Enhancing the epistemological and practical utility of qualitative research findings. International Journal of Nursing Studies, 46, 1401-1410. 
Denzin, N. K., \& Lincoln, Y. S. (2005). Introduction: The discipline and practice of qualitative research. In N. K. Denzin \& Y. S. Lincoln (Eds.) The Sage handbook of qualitative research ( $3^{\text {rd }}$ ed., pp. 1-32). Thousand Oaks, CA: Sage Publications.

Diemer, M. A. (2007). Two worlds: African American men's negotiation of predominantly White educational and occupational worlds. Journal of Multicultural Counseling and Development, 35, 2-14.

Dos Santos-Zingala, M., \& McColl, M. A. (2006). Disability and participation in post-conflict situations: The case of Sierra Leone. Disability \& Society, 21, 243-257.

Eide, P., \& Allen, C. B. (2005). Recruiting transcultural qualitative research participants: A conceptual model. International Journal of Qualitative Methods, 4, 44-56.

Fassinger, R. E. (2005). Paradigms, praxis, problems, and promise: Grounded theory in counseling psychology research. Journal of Counseling Psychology, 52, 156-166.

Fouad, N. A., \& Arredondo, P. (2007). Becoming culturally oriented: Practical advice for psychologists and educators. Washington, D.C.: American Psychological Association.

Fouad, N. A., Gerstein, L. H., \& Toporek, R. L. (2006). Social justice and counseling psychology in context. In R. L. Toporek, L. H. Gerstein, N. A. Fouad, G. Roysircar, T. Israel (Eds.). Handbook for social justice in counseling psychology: Leadership, vision, and action (pp. 1-16). Thousand Oaks, CA: Sage Publications.

Glaser, B. G., \& Strauss, A. L. (1967). The discovery of grounded theory: Strategies for qualitative analysis. New York, NY: Aldine.

Grayshield, L. \& Mihecoby, A. (2010). Indigenous ways of knowing as a philosophical base for the promotion of peace and justice in counseling education and psychology. Journal for Social Action in Counseling and Psychology, 2, 1-16.

Guishard, M., Fine, M., Doyle, C. Jackson, J., Staten, T., \& Webb, A. (2005). The Bronx on the move: Participatory consultation with mothers and youth. Journal of Educational and Psychological Consultation, 16, 35-54.

Herek, G. M., Kimmel, D. C., Amaro, H., \& Melton, G. B. (1991). Avoiding heterosexist bias in psychological research. American Psychologist, 46, 957-963.

Hill, C. H., Thompson, B. J., \& Williams, E. N. (1997). A guide to conducting consensual qualitative research. The Counseling Psychologist, 25, 517-572.

Hill, C. E., Knox, S., Thompson, B. J., Williams, E. N., Hess, S. A., \& Ladany, N. (2005). Consensual qualitative research: An update. Journal of Counseling Psychology 52, 196205. 
Lassiter, P. S., Dew, B. J., Newton, K., Hays, D. G., \& Yarbrough, B. (2006). Self-defined empowerment for gay and lesbian parents: A qualitative examination. The Family Journal, 14, 245-252.

Lewis, J. A., Ratts, M. J., Paladino, D. A., \& Toporek, R. L. (2011). Social justice counseling and advocacy: Developing new leadership roles and advocacy. Journal for Social Action in Counseling and Psychology, 3, 5-16.

Lockyer, J. (1998). Needs assessment: lessons learned. Journal of Continuing Education in the Health Professions, 18, 190-192.

Lyons, H. Z., \& Bike, D. H. (2010). Designing and interpreting qualitative research in multicultural counseling. In J. G. Ponterotto, J. M. Casas, L. A. Suzuki, \& C. M. Alexander (Eds.), Handbook of multicultural counseling ( $3^{\text {rd }}$ ed., pp. 413-425). Thousand Oaks, CA: Sage Publications.

Lyons, H. Z., Evans, A. J. J., White, M. M., Nichols, T., \& Leckey, J. (in preparation). Meanings ascribed to work by African American women experiencing chronic unemployment.

Malone, R. E., Yerger, V. B., McGruder, C. O., \& Froelicher, E. (2006). "It's like Tuskegee in reverse": A case study of ethical tensions in Institutional Review Board review of community-based participatory research. American Journal of Public Health, 96, 19141919.

Marshall, C., \& Rossman, G. B. (2006). Designing qualitative research (4 $4^{\text {th }}$ ed.). Thousand Oaks, CA: Sage Publications.

McGuire, T. G., \& Miranda, J. (2008). New evidence regarding racial and ethnic disparities in mental health: Policy implications. Health Affairs, 27, 393-403.

Merchant, M., \& Dupuy, P. (1996). Multicultural counseling and qualitative research: Shared worldview and skills. Journal of Counseling \& Development, 74, 537-41.

Montero, M. (2009). Community action and research as citizenship construction. American Journal of Community Psychology, 43, 149-161.

Morrow, S. L. (2005). Quality and trustworthiness in qualitative research in counseling psychology. Journal of Counseling Psychology, 52, 250-260.

Morrow, S. L., Rakhsha, G., \& Castañeda, C. L. (2001). Qualitative research methods for multicultural counseling. In J. G. Ponterotto, J. M. Casas, L. A. Suzuki, \& C. M. Alexander (Eds.), Handbook of multicultural counseling (2nd ed., pp. 575-603). Thousand Oaks, CA: Sage Publications.

Noonan, B. M., Gallor, S. M., Hensler-McGinnis, N. F., Fassinger, R. E., Wang, S., \& Goodman, J. (2004). Challenge and success: A qualitative study of the career development of highly achieving women with physical and sensory disabilities. Journal of Counseling Psychology, 51, 68-80. 
Ponterotto, J. G. (2002). Qualitative research methods: The fifth force in psychology. The Counseling Psychologist, 30, 394-406.

Ponterotto, J. G. (2005). Qualitative research in counseling psychology: A primer on research paradigms and philosophy of science. Journal of Counseling Psychology, 52, 126-136.

Ratts, M., D'Andrea, M., \& Arredondo, P. (2004). Social justice counseling: 'Fifth force' in field. Counseling Today, 47, 28-30.

Reviere, R. (1996). Needs assessment: A creative and practical guide for social scientists. Bristol, PA: Taylor and Francis.

Sanders, J. L. (2000). Advocacy on behalf of African American clients. In J. Lewis \& L. J. Bradley (Eds.), Advocacy in counseling: Counselors, clients, \& community. Greensboro, NC: Caps Publications.

Shinnar, R. S. (2007). A qualitative examination of Mexican immigrants' career development: Perceived barriers and motivators. Journal of Career Development, 33, 338-375.

Simpson, G. M., \& Lawrence-Webb, C. L. (2009). Responsibility without community resources: Informal kinship care among low-income, African American grandmother caregivers. Journal of Black Studies, 39, 825-847.

Sixsmith, J., Boneham, M., \& Goldring, J. E. (2003). Accessing the community: Gaining insider perspectives from the outside. Qualitative Health Research, 13, 578- 589.

Smith, L. T. (2012). Decolonizing methodologies: Research and indigenous peoples (2nd ed.). London: Zed Books.

Smythe, W. E., \& Murray, M. J. (2000). Owning the story: Ethical considerations in narrative research. Ethics \& Behavior, 10, 311-336.

Stufflebeam, D. L., McCormick, C. H., Brinkerhoff, R. O., Nelson, C. O. (1985). Conducting educational needs assessment. Boston, MA: Kluwer Nijhoff.

Sue, D. W., Arredondo, P., \& McDavis, R. J. (1992). Multicultural counseling competencies and standards: A call to the profession. Journal of Counseling \& Development, 70, 477-486.

Vera, E.M., \& Speight, S. L. (2003). Multicultural competence, social justice, and counseling psychology: Expanding our roles. The Counseling Psychologist, 31, 253-272.

Washington, H. A. (2006). Medical apartheid: The dark history of medical experimentation on Black Americans from colonial times to the present. New York, NY: Doubleday.

Wolcott, H. F. (1994). Transforming qualitative data: Description, analysis, and interpretation. Thousand Oaks, CA: Sage. 